\title{
Способы образования простых личных имен тувинцев"
}

\author{
Надежда Д. Сувандии \\ Тувинский государственный университет, Российская Федерация
}

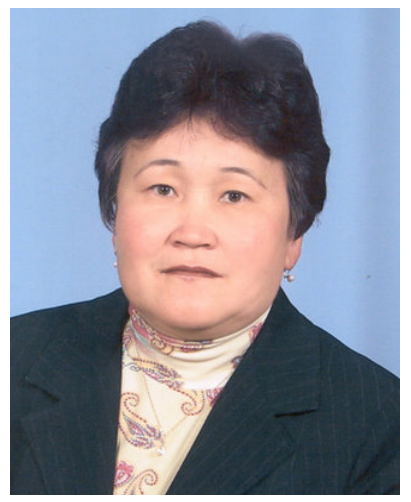

В статье представлены наиболее распространенные способы образования простых личных имен (антропонимов) в тувинском языке.

Материалом исследования послужили более 500 личных имен, собранных автором в 2019 г. во время лингвистических экспедиций к тувинцам Монголии (сумоны Цэнгэл Баян-Ульгийского аймака и Буянт Ховдского аймаков) и по ряду районов Тувы: МонгунТайгинскому, Овюрскому, Бай-Тайгинскому, Барун-Хемчикскому, Дзун-Хемчикскому. Анализировался также архив личных имен, собранных автором в экспедициях за 20 лет. Имена подразделяются на простые непроизводные и простые производные. Первые образованы лексико-семантическим способом словообразования; от нарицательных слов из различных семантических групп лексики. Вторые (большая часть) - морфологическим способом: с помощью добавления различных аффиксов по соответствующим моделям (выявлено более 15 моделей).

Ключевые слова: ономастика; тувинский язык; Тува; личное имя; лексико-семантический способ; морфологический способ; аффикс; антропоформант

"Работа выполнена при финансовой поддержке РФФИ в рамках научного проекта № 19-012-00073 «Трансформационные процессы в ономастике народов Центральной Азии: история и современность (на примере Тувы, Тофаларии, Калмыкии и Монголии».

\section{Для цитирования:}

Сувандии Н. Д. Способы образования простых личных имен тувинцев [Электронный ресурс] // Новые исследования Тувы. 2020, № 1. URL: https://nit.tuva.asia/nit/article/view/911 (дата обращения: дд.мм.гг.). DOI: 10.25178/ nit.2020.1.7

Сувандии Надежда Дарыевна - кандидат филологических наук, декан филологического факультета Тувинского государственного университета. Адрес: 667004, Россия, г. Кызыл, ул. Педагогическая, д. 13. Тел.: +7 (923) 268-93-69. Эл. адрес: suvandiin@mail.ru ORCID ID:0000-0002-3817-2436

Suvandii Nadezhda Daryevna, Candidate of Philology, Dean, Faculty of Philology, Tuvan State University. Postal address: 13 Pedagogicheskaya St., 667004 Kyzyl, Russian Federation. Tel.: +7 (923) 268-93-69. E-mail: suvandiin@mail.ru 


\title{
Methods of formation of simple personal names in Tuvan"
}

\author{
Nadezhda D. Suvandii \\ Tuvan State University, Russian Federation
}

\begin{abstract}
The article presents an overview of the most widespread methods of forming simple personal names, or anthroponyms, in Tuvan language.

The sources for the study were over 500 personal names collected by the author in 2019 in the course of linguistic expedition to Mongolian Tuvans (sum Tsengel, Bayan Ölgii aimag, and sum Buyant, Khovd aimag), as well as in several rayons of Tuva: Mongun-Taigin, Ovyur, Bay-Tangin, Barun-Khemchik and Dzun-Khemchik. The author also used entries on personal names from the archives of her expeditions for the previous twenty years.

Personal names have been found to fall into two groups: simple productive and simple non-productive. The latter were formed by the lexico-semantical method from common nouns belonging to a variety of semantic groups. The former much larger, group was formed morphologically, by adding to the stem one of the plethora of affixes in accordance to a particular model, 15 of which have been identified.
\end{abstract}

Keywords: onomastics; Tuvan language; Tuva; personal name; lexico-semantical method; morphological method; affix; anthropofomant

\footnotetext{
" The article was written with financial support from the Russian Foundation for Basic Research as part of project No. 19-012-00073 "Transformational processes in Central Asian onomastics: history and contemporary state: the cases of Tuva, Tofalaria, Kalmykia and Mongolia".
}

\section{For citation:}

Suvandii N. D. Methods of formation of simple personal names in Tuvan. The New Research of Tuva. 2020, № 1 [online] Available at: https://nit.tuva.asia/nit/article/view/911(access date ...). DOI: 10.25178/nit.2020.1.7

\section{Введение}

Собственное имя - это слово, словосочетание или предложение, которое служит для выделения именуемого им объекта из ряда подобных, индивидуализируя и идентифицируя данный объект. К собственным именам относятся антропонимы - собственные имена людей, топонимы - собственные наименования географических объектов, теонимы - собственные имена божеств, зоонимы - собственные имена или клички животных и т. д. (Лингвистический энциклопедический словарь, 1990: 473).

В данной статье рассматриваются основные способы образования простых личных имен в тувинском языке, которые ранее отдельным объектом специального научного исследования не являлись. Работа продолжает наши исследования по проблемам тувинской антропонимии, которыми мы занимаемся с конца 1990-х гг. (Сувандии, 2011). Также простые личные имена в тувинском языке рассматривались ранее (Чадамба, 1993: 98; Сувандии, 2011: 40-50), однако, непосредственно тема способов еще не раскрывалась.

Источниковую базу исследования составили собственные имена - более 500 личных имен, собранные нами во время комплексной экспедиции 2019 г. при поддержке гранта Российского фонда фундаментальных исследований (РФФИ) по проекту «Трансформационные процессы ономастики народов Центральной Азии: история и современность (на примере Тувы, Тофаларии, Калмыкии и Монголии)» (№ 19-012-00073, 2019) в Ховдский, Баян-Ульгийский аймаки Западной Монголии, а также в западные районы Республики Тыва. Также анализ включал и данные из нашего архива, собранного в целом за последние 20 лет в экспедициях. 


\section{Из истории изучения антропонимии тувинского языка}

Основу изучения ономастики (раздела языкознания, изучающего любые собственные имена) тувинского языка составили работы первых исследователей тувинского языка еще во второй половине XIX столетия в работах Н. Ф. Катанова (Катанов, 1903, 2011), С. Е. Малова (Малов, 1951), И. В. Кормушина (Кормушин, 1997) и др.,

С 60-х гг. XX столетия специальными научными исследованиями по вопросам ономастики стали заниматься и ученые-тувиноведы.

Исследованию антропонимов посвящены работы таких ученых, как 3. Б. Чадамба (Чадамба, 1979, 1993), где автор дает списки личных имен, частичное описание их структуры и мнение о происхождении, С. И. Вайнштейн (Вайнштейн, 1969, 1989), в которой описаны личные имена, прозвища, обычаи и традиции наречения именем, а также некоторые вопросы иноязычных имен. Д. А. Монгуш в одной из своих работ остановился на сокращенных формах личных имен в художественной литературе (Монгуш, 1973). О заимствованных личных именах монгольско-тибетского происхождения писали К. А. Бичелдей (Бичелдей, 1993) и Р. Д. Лудуп (Лудуп, 1996). В наших работах также описаны основные лексико-семантические группы, структурные типы, происхождение, динамика употребления личных имен конца 1990-х - начала 2000-х годов (Сувандии, 2009, 2011, 2013, 2019ab).

В тувинской антропонимии вопросы образования личных имен являются одним из мало изученных и актуальных проблем. Автором данной статьи изучено образование сложных имен в тувинском языке (Сувандии, 2019b), в основном синтаксическим способом словообразования. На этот раз мы рассмотрим образование простых личных имен.

\section{Лексико-семантический способ образования собственных имен}

Простые непроизводные антропонимы образованы лексико-семантическим способом словообразования. По мнению В. В. Виноградова, «...лексико-семантический - это способ формирования онимов путем распада одного слова на два» (Виноградов, 1975: 156). Как пишет В. Н. Немченко, «при лексикосемантическом способе словообразования новые слова возникают в результате изменения лексических значений существующих в языке слов при сохранении их материальной структуры, звукового состава. Основным (и единственным) словообразовательным средством при данном способе является изменение лексического значения слова» (Немченко, 1984: 117). Е. И. Диброва и др. отмечают, что «лексико-семантический неморфологический способ - это образование нового слова в результате изменения значения уже существующей в языке лексической единицы (Диброва и др., 2008: 445).

В тувинской ономастике немало собственных имен - антропонимов, топонимов, зоонимов, образованных от нарицательной лексики. Известный классик российской и советской ономастики А. В. Суперанская отметила в своей работе, что непроизводные собственные имена существуют «без специальных ономастических формантов, топонимизацией аппелятива ...» (Суперанская, 1969: 93), поэтому они образованы из нарицательных слов без формантов.

3. Б. Чадамба - один из первых ученых, которая стала заниматься исследованием личных имен тувинского языка, в своей работе пишет, что «... традиция образовывать личные имена от нарицательных сохранилась у тувинцев по сей день и является наиболее распространенным способом имяобразования» (Чадамба, 1993: 98).

Непроизводные собственные имена, в первую очередь, образованы от имен существительных и прилагательных, притом различных лексико-семантических групп:

1. от названий домашних и диких животных, птиц и насекомых: Адыг, Адыг-оол /м/ - от адыг - 'медведь', Анай-кыс, Анай /ж/, Анай-оол/м/ - от анай - 'козленок', Буга /м/ - от буга - 'бык', Хураган /м, ж/ от хураган - 'ягненок', Булана Булаана /ж/ - от булан - 'самка лося, лосиха', Ангыр /м, ж/ - от ангыр аңгыр - 'турпан', Ары /M/ - от ары - ‘пчела' и др. Особенностью описанной группы отмечается наличие «общих», относящихся как к мужским, так и женским, имен;

2. от названий растительности: Агы /ж/ - от агы - 'полынь', Аpтыш /M/ - от артыш - 'можжевельник', Мочурга /ж/ - от мочурга - 'сережка тополя', Чечек /ж/ - от чечек - 'цветок', Чимис /м, ж/ - от чимис - 'плод, фрукт', Чингис /м, ж/ - от чингис - 'мох', Чочагай /ж/ - от чочагай - 'шишка' и т. п. Личные имена данной группы отличаются от других тем, что большая часть собранных антропонимов относятся к женским; 
3. от нарицательных имен существительных, характеризующих внешние особенности носителя имени: Орлан /м/ - от орлан - ‘бойкий, живой’, Эрес /м/ - от эрес - ‘храбрый’, Мерген /м/ - от мерген 'мудрый’, Омак /м/ - от омак - 'веселый, бодрый, живой’, Сергек /м/ - от сергек - ‘бодрый, живой’ и т. д. В данной группе имен зафиксированы только мужские личные имена, что указывает на характерную ее особенность;

4. от нарицательных имен, отражающих цветовые характеристики денотата: Кызыл /M/ - от кызыл ‘красный’ (ребенок при рождении был очень красным), Хүрең /ж/ - от хүрең - ‘коричневый’ (новорожденный со смуглой кожей), Кара /м, ж/ - от кара - 'черный’ (ребенок с темной кожей) и др. В отличие от предыдущих, в данной группе непроизводные личные имена встречаются редко;

5. от нарицательных имен, обозначающих названия природных явлений: Сылдыс /м, ж/ - от сылдыс - ‘звезда', Шолбан /м, ж/ - от шолбан - ‘яркая звезда’, Чайынды /ж/ - от чайынды - ‘наледь’, Чаңнык /м/ - от чаңнык - 'молния', Челээш /ж/ - от челээш - 'радуга', Үгер /ж/ - от ұгер - 'Плеяды', Солаңзы /ж/ - от солаңгы - ‘зарево’, Меңги /м, ж/ - от меңги - ‘ледник, вечный снег’ и т. п.;

6. от нарицательных имен, указывающих на национально-бытовые принадлежности этноса: Деспи /м/ - от деспи - 'корыто', Савааш /ж/ - от савааш - 'шерстобитный прут, смычок', Саадак /м/ - от саадак - 'колчан; охотничья сумка', Сыдым /м/ - от сыдым - 'кожаный аркан', Шүүче /м/ - от шүүче 'стамеска' и др.;

7. от нарицательных имен, обозначающих названия национальных украшений: Билзек /ж/ - от билзек - ‘кольцо, перстень', Шуру /ж/ - от шуру - ‘бусина, бусы', Чинчи /ж/ - от чинчи - ‘бусина, бисер’, Чаныы /м/ - от чаныы - ‘брусок, оселок, мягкий точильный камень’ и т. д. Большая часть личных имен данной лексико-семантической группы являются женскими.

Таким образом, в качестве непроизводных личных имен, образованных лексико-семантическим способом словообразования, употребляются антропонимы 7 основных семантических групп, которые указывают на имятворчество тувинского этноса. Следует также отметить, что в некоторых группах встречаются только мужские личные имена, в частности, антропонимы, характеризующие внешние особенности денотата. В антропонимах, образованных от названий украшений, почти все зафиксированные личные имена являются женскими.

\section{Морфологический способ образования личных имен}

В тувинской ономастике большая часть собственных имен образованы морфологическим способом, когда новые слова образуются с помощью аффиксов (Виноградов, 1975: 158).

Одним из распространенных в образовании личных имен являются уменьшительно-ласкательные аффиксы (антропоформанты), которые с древних времен по настоящее время активно употребляющиеся в качестве имяобразовательных:

-пай/-бай/-май... по модели имя сущ. (прил.) + -пай: Чарашпай /м, ж/ - от чараш - ‘красивый’ и афф. -пай; Адыгбай /м/ - от адыг - 'медведь' и афф. -бай; Хөвенмей Ховенмей /м/ - от хөвең - 'вата’ и афф. -мей и т. д.;

-чык/-жык...по модели имя сущ. (прил.) + -чык: Боражык /м/ - от бора - 'серый’ и афф. -жык; Далганчык /M/ - от далган - 'мука’ и афф. -чык; Чалаажык /ж/ - от чалаа - ‘лента на головном уборе’ и афф. -жык и др.;

-кай/-кей...по модели имя сущ. + -кай: Кежиккей /ж/ - от кежик - 'дар, благо; добро, достояние, богатство’ и афф. -кей; Ашаккай /м/ - от ашак - ‘пожилой мужчина, старик’ и афф. -кай; Кестиккей /м/ - от кестик - ‘ножик' и афф. -кей и т. п.;

- ак/-ек...по модели имя сущ. (прил.) + -ак: Сыынак /м/ - от сыьын - ‘марал’ и афф. -ак; Хеймерек /м, ж/ - от хеймер - ‘самый младший’ и афф. -ек; Самдарак /м/ - от самдар - ‘дырявый, оборванный’ и афф. -ак и т. д.;

-ай/-ей...по модели имя сущ. + -ай: Шолбанай /ж/ - от шолбан - ‘яркая звезда; Венера' и афф. -ай; Долбанай /ж/ - от долбан - 'румянец' и афф. -ай и др.

Большую часть производных от уменьшительно-ласкательных аффиксов антропонимов составляют личные имена, образованные по моделям: имя сущ. (прил.) + -nай, имя сущ. + -кай, а по остальным выявленным моделям зафиксированы единичные. 
Одной из особой группой производных личных имен следует отметить антропонимы, образованные производными нарицательными именами, причем указывающими на основные виды деятельности этноса.

К ним относятся следующие личные имена, образованные при помощи следующих словообразовательных аффиксов:

-чы/-чи... по модели имя сущ. + -чы: Чылгычы /м/ - от чылгы - 'табун' и афф. -чы букв. 'табунщик’; Аңцчы /м/ - от аң - 'зверь' и аф.. -чы, букв. 'охотник'; Аяжы /м/ - от ая - 'самострел' и афф. -жы, букв. 'охотник с самострелом', Саанчы /ж/ - от саан - ‘дойный скот’ и афф. -чы, букв. 'доярка' и т. д.;

-кчы/-кчи... по модели: глагол + -кчы: Чаяакчы /м/ - от чаяа- - ‘твори, создавай’ и афф. -кчы, букв. ‘создатель, творец’, Тиилекчи /м/ - от тииле- - ‘побеждай’ и афф. -кчи, букв. 'победитель', Салгакчы /м/ - от салга- - ‘наследовать, унаследовать’ и афф. -кчы, букв. 'наследник’ и др.;

-чын/-чин по модели имя сущ. + -чы: Малчын /м/ - от мал - 'скот' и афф. -чын, букв. 'животновод, скотовод’; Тараачын /м, ж/ - от тараа - ‘хлеб, зерно’ и афф. -чын, букв. 'земледелец, хлебороб’ и др.

Есть немногие личные имена, образованные от других производных нарицательных имен существительных, прилагательных и глагола по различным моделям

имя суи. + -тук: Оттук /м/ - от от - 'огонь' + афф. -тук;

имя сущ. + -лыг: Чолдуг /м/ - от чол - 'судьба, доля, счастье’ и афф. -дуг; Салдыг /м/ - от сал - ‘борода’ + афф. -дыг; Олчалыг /ж/ - от олча - ‘находка, добыча’ + аф. -лыг;

глагол + -ар: Адар /м/ - от ат- - 'стрелять, стреляй’ и афф. -ар и т. д.

В тувинской антропонимической системе имеются аффиксы, образующие только личные имена, например, -лдей/-лдай... по модели: имя. сущ. + -лдай: Каралдай /м/ - от кара - 'черный’ и афф. -лдай; Сүгелдей $/$ м/ - от сүге балды - 'топор' и др., которые в современном тувинском именнике почти не фиксируются.

К подобным личным именам следует отнести и модель: имя числ. + - дай/...: Бежендей/м/ - от бежен - ‘пятьдесят' и афф. -дей; Чедендей /м/ - от чеден - 'семьдесят' и афф. -дей, которые в настоящее время хоть редко, но встречаются в антропонимии тувинского языка, начиная с 2000-х годов.

В производных личных именах тувинского языка особое место занимают такие имяобразующие аффиксы, как -маа $u$-на, которые образуют только женские личные имена. Нужно также отметить, что аффикс -маа со значением 'мать' заимствован с тибетского языка (Сувандии, 2011: 48).

Личные имена с аффиксом -маа в тувинском языке являлись часто употребительными с древних времен в соответствии с обычаями имянаречения. По данному обычаю если в семье новорожденные дети часто умирали от различных болезней, то мальчиков, чтобы ввести в заблуждение злых духов болезни, нарекали женскими именами, а девочек - мужскими. Подобные имена в настоящее время зафиксированы у пожилых носителей как женского, так и мужского пола: Селикмаа /м, ж/ - от селик ‘имущество, приданое невесте’ и афф. -маа, Хандымаа /ж/ - от ханды - ‘настойка’ и афф. -маa.

В системе современных личных имен тувинского языка антропоформант -маа, как показатель жен-

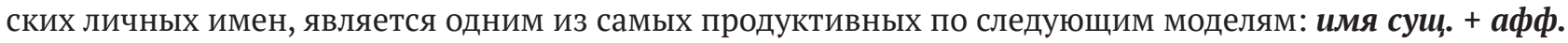
-маa: Аңзгырмаа - от аңзьыр - ‘турпан' и афф. -маа; Байырмаа /ж/ - от байыр - 'праздник, торжество’ и афф. -маа; Кежикмаа /ж/ - от кежик - ‘дар, благо; добро’ и афф. -маа и т. д.

Следующая модель похожая, но образованная от имен прилагательных: имя прилаг. + -мaа: Ажыкмаa /ж/ - от ажык - 'открытый’ и афф. -маa; Сергекмаа /ж/ - от сергек - ‘бодрый, живой’ и афф. -маа; Мергенмаа /ж/ - от мерген - 'мудрый’ и афф. -маа и т. д.

Отдельной группой следует также отметить личные имена, образованные в большинстве от мужских антропонимов при помощи аффикса - $a$, восходящего к окончанию женского рода в русском языке по модели: имя сущ. + - $\boldsymbol{a}$ : Аяна - от мужского имени Аян, образованного от слова аян - 'внешний облик' и афф. - $a$; Херела - от имени Херел, образованного от слова херел - ‘луч’ и афф. - $а$; Чаяана - от имени Чаяан, образованного от чаяан - 'судьба, доля, участь'и афф. - $а$ и т. д.

В антропонимии тувинского языке очень много женских личных имен, образованных от нарицательных слов по модели: имя сущ. + -на: Кулчана - от кулча - 'дикий лук' и афф. -на; Хенчена - от хенче - ‘рожденный осенью мелкий рогатый скот' и афф. -на; Олчана - от олча - 'находка, добыча' и афф. -на и т. п.

Таким образом, простые личные имена в тувинском языке образуются только двумя способами словообразования: лексико-семантическим и морфологическими. 


\section{Заключение}

В тувинской антропонимии немало простых производных и непроизводных личных имен. Непроизводные личные имена, как указано выше, образованы лексико-семантическим способом от различных лексико-семантических групп лексики тувинского языка. Среди выявленных лексико-семантических групп особо следует отметить личные имена, образованные от названий домашних и диких животных, национально-бытовых принадлежностей, указывающих на особенности кочевого образа жизни и хозяйственной деятельности тувинского этноса. Особо можно также выделить и антропонимы, образованные от названия украшений, которые в большей степени являются женскими именами.

Производные личные имена образованы также одним из основных способов словообразования морфологическим при помощи различных аффиксов. Среди аффиксов следует особо можно отметить уменьшительно-ласкательные аффиксы типа -naŭ/..., -чыk/..., -ak/.., которые активно употребляются в образовании личных имен. В тувинском имятворчестве отличаются и производные антропонимы, образованные аффиксами -чы/..., -кчы/..., -чын/..., указывающие на род занятий представителей этноса.

Среди производных личных имен тувинского языка имеются аффиксы, которые образуют только женские антропонимы, например, -маa, -на, -a., последние из которых заимствованы из русского языка, как показатели окончания женского рода, которые в настоящее время также являются одним из активных аффиксов имяобразования.

В результате словообразовательного анализа вывялено боле 15 моделей образования производных личных имен, среди которых большую группу составляют модели имя сущ. + уменьш.-ласк афф., имя $c y щ .+-$ - $/ \ldots$... (-кчы/...), имя сущ. + -маа. Зафиксированы и некоторые единичные модели, как глагол + - $a p$, имя числ. +-ей.

Таким образом, в тувинской антропонимической системе простые непроизводные и производные личные имена образованы теми же способами, что и в других тюркских языках, в частности, в казахском (Кульдеева, 2001), в якутском (Николаев, 2018) и др.

\section{СПИСОК ЛИТЕРАТУРЫ}

Бичелдей, К. А. (1993) Тыва болгаш өске дылдар // Тыва дыл болгаш чугаа культуразы [Тувинский язык и культура речи] / отв. редакторы: К.А. Бичелдей, Ч. М. Доржу, Ш. Ч. Сат. Кызыл : Тываның ном үндүрер чери. 103 с. С. 62-75. (На тув. яз.)

Вайнштейн, С. И. (1969) Личные имена, термины родства и прозвища у тувинцев // Ономастика / ред. В. А. Никонов и А. В. Суперанская. М. : Наука. 261 с. С. 125-132.

Вайнштейн, С. И. (1989) Тувинцы // Системы личных имен у народов мира / ред. Р. Ш. Джарылгасинова, М. В. Крюков, В. А. Никонов, А. М. Решетов. М. : Наука. 383 с. С. 305-307.

Виноградов, В. В. (1975) Вопросы современного русского словообразования // Исследования по русской грамматике / отв. ред. М. Ю. Шведова М. : Наука. 559 с. С. 551-554.

Диброва, Е. И., Касаткин, Л. Л., Николина, Н. А., Щеболева, И. И. (2008) Современный русский язык. Теория. Анализ языковых единиц: в 2 ч. М. : Академия. Ч. 1. 479 с.

Катанов, Н. Ф. (1903) Опытъ изслъдованія урянхайскаго языка, съ указаніемъ главнъйшихъ родственныхъ отношеній его къ другимъ языкамъ тюркскаго корня. Казань : Типо-литографія Императорскаго Казанскаго Университета. 1600 с.

Катанов, Н. Ф. (2011) Очерки урянхайской земли. Дневник путешествия, исполненного в 1889 году / Подготовка рукописи к печати, вступительное слово и комментарий А. К. Кужугет. Кызыл : ТИГПИ при Правительстве РТ. 383 с.

Кормушин, И. В. (1997) Тюркские енисейские эпитафии. Тексты и исследования / отв. ред. Э. Р. Тенишев. М. : Наука. 303 с.

Кульдеева, Г. И. (2001) Антропонимическая система современного казахского языка : автореф. дисс. ... докт. филол. н. Казань. 60 с.

Лингвистический энциклопедический словарь (1990) / гл. ред. В. Н. Ярцева. М. : Сов. Энциклопедия. 688 c.

Лудуп, Р. Д. (1996) Адың-шолаң чажыттары [Тайны имени твоего] // журнал Башкы № 6. С. 47-49; №. 7. С. 51-53. (На тув. яз.). 
Малов, С. Е. (1951) Памятники древнетюркской письменности. Тексты и исследования. М.; Л. : Издво АН СССР. 451 c.

Монгуш, Д. А. (1973) Сокращенная форма тувинских личных имен // Ученые записки ТНИИЯлИ. Вып.XVI. Кызыл. С. 146-155.

Немченко, В. В. (1984) Современный русский язык. Словообразование. М.: Высшая школа. 255 с.

Николаев, Е. Р. (2018) Якутские личные имена (лингвокультурологический аспект) : автореф. дисс.... канд. филол. н. Якутск. 26 с.

Сувандии, Н. Д. (2009) Интернациональные антропонимы в тувинском именнике // Сибирский филологический журнал. № 2. С. 157-163.

Сувандии, Н. Д. (2011) Тувинская антропонимия. Кызыл : Редакционно-издательский отдел Тувинского государственного университета издательства. 207 с.

Сувандии, Н. Д. (2013) Современное состояние изучения ономастики тувиского языка // Мир науки, культуры, образования № 6. С. 362-364.

Сувандии, Н. Д. (2018) Вклад Бичен Кыргысовны Ондар в развитие топонимики Тувы [Электронный ресурс] // Новые исследования Тувы. № 3. URL: https://nit.tuva.asia/nit/article/view/785 (дата обращения: 12.12.2019). DOI: 10.25178/nit.2018.3.1

Сувандии, Н. Д. (2019а) Официальные и «вторые» имена этнических тувинцев Монголии // Oriental Studies № 4. C. 661-668. DOI: 10.22162/2619-0990-2019-44-4-661-668

Сувандии Н. Д. (2019b) Сложные личные имена, образованные именными частями речи в тувинском языке // Мир науки, культуры, образования № 3. С. 404-406.

Суперанская, А. В. (1969) Структура имени собственного. Фонология и морфология. М. : Наука. 206 с.

Чадамба, 3. Б. (1999) Тувинские имена // Справочник личных имен народов РСФСР / под ред. А. В. Суперанской, Ю. М. Гусева М. : Русский язык. 571 с. С. 174-177.

Чадамба, 3. Б. (1993) Способы образования тувинских личных имен // Вопросы тувинского языкознания / отв. ред. Д. А. Монгуш, Б. И. Татаринцев. Кызыл : Новости Тувы. 128 с. С. 98-105.

Дата поступления: 20.12.2019 г.

\section{REFERENCES}

Bicheldei, K. A. (1993) Tyva bolgash öske dyldar [Tuvan language and other languages]. In: Tyva dyl bolgash chugaa kul'turazy [Tuvan language and culture of speech] / ed. by K. A. Bicheldei, Ch. M. Dorzhu and Sh. Ch. Sat. Kyzyl, Tuvan book publishing house. 103 p. Pp. 62-75. (In Tuv.)

Weinstein, S. I. (1969) Lichnye imena, terminy rodstva i prozvishcha u tuvintsev [Personal names, kinship terms and nicknames among Tuvans]. In: Onomastika [Onomastics] / ed. by V. A. Nikonov and A. V. Superanskaia. Moscow, Nauka. 261 p. Pp. 125-132. (In Russ.).

Weinstein, S. I. (1989) Tuvintsy [Tuvans]. In: Sistemy lichnykh imen u narodov mira [Systems of personal names among the peoples of the world] / ed. by R. Sh. Dzharylgasinova, M. V. Kriukov, V. A. Nikonov and A. M. Reshetov. Moscow, Nauka. 383 p. Pp. 305-307. (In Russ.).

Vinogradov, V. V. (1975) Voprosy sovremennogo russkogo slovoobrazovaniia [The issues of contemporary Russian word-formation]. In: Issledovaniia po russkoi grammatike [Studies in Russian grammar] / ed. by M. Yu. Shvedova Moscow, Nauka. 559 p. Pp. 551-554. (In Russ.).

Dibrova, E. I., Kasatkin, L. L., Nikolina, N. A. and Shcheboleva, I. I. (2008) Sovremennyi russkii iazyk. Teoriia. Analiz iazykovykh edinits [Contemporary Russian language. Theory. Analysis of language units]: in 2 parts. Moscow, Akademiia. Part 1. 479 p. (In Russ.).

Katanov, N. F. (1903) Opyt izsledovaniia uriankhaiskago iazyka, s ukazaniem glavneishikh rodstvennykh otnoshenii ego $k$ drugim iazykam tiurkskago kornia [A study of the Uriankhai language, with the indication of its main relations to other languages of the Turkic root]. Kazan', Tipo-litografiia Imperatorskago Kazanskago Universiteta. 1600 p. (In Russ.).

Katanov, N. F. (2011) Ocherki uriankhaiskoi zemli. Dnevnik puteshestviia, ispolnennogo $v 1889$ godu [Essays on the Uriankhai land. Diary of a journey made in 1889]. Preparation of the manuscript for printing, introduction and commentary by A. K. Kuzhuget. Kyzyl, TIGPI pri Pravitel'stve RT. 383 p. (In Russ.).

Kormushin, I. V. (1997) Tiurkskie eniseiskie epitafii. Teksty i issledovaniia [Turkic Yenisei epitaphs. Texts and studies], ed. by E. R. Tenishev. Moscow, Nauka. 303 p. (In Russ.). 
Kul'deeva, G. I. (2001) Antroponimicheskaia sistema sovremennogo kazakhskogo iazyka [The anthroponymic system of the modern Kazakh language]: Thesis of Diss.... Doctor of Philology. Kazan'. 60 p. (In Russ.).

Lingvisticheskii entsiklopedicheskii slovar' [An encyclopedic dictionary of linguistics] (1990) / chief editor V. N. Iartseva. Moscow, Sov. Entsiklopediia. 688 p. (In Russ.).

Ludup, R. D. (1996) Adyng-sholang chazhyttary [The Mysteries of your name]. Bashky, no. 6, pp. 47-49; no. 7, pp. 51-53. (In Tuv.).

Malov, S. E. (1951) Pamiatniki drevnetiurkskoi pis'mennosti. Teksty $i$ issledovaniia [Monuments of ancient Turkic writing. Texts and research]. Moscow, Leningrad, AN SSSR Publ. Vol. 1.451 p. (In Russ.).

Mongush, D. A. (1973) Sokrashchennaia forma tuvinskikh lichnykh imen [Abbreviated forms of Tuvan personal names]. Uchenye zapiski TNIIIaLI, vol. XVI. Kyzyl. Pp. 146-155. (In Russ.).

Nemchenko, V. V. (1984) Sovremennyi russkii iazyk. Slovoobrazovanie [Contemporary Russian language: Word-formation]. Moscow, Vysshaia shkola. 255 p. (In Russ.).

Nikolaev, E. R. (2018) Yakutskie lichnye imena (lingvokul'turologicheskii aspekt) [Yakut personal names: the linguoculturological aspect]: Thesis of Diss.... Candidate of Philology. Yakutsk. 26 p. (In Russ.).

Suvandii, N. D. (2009) Internatsional'nye antroponimy v tuvinskom imennike [International anthroponyms in the Tuvan name book]. Sibirskii filologicheskii journal, no. 2, pp. 157-163. (In Russ.).

Suvandii, N. D. (2011) Tuvinskaia antroponimiia [Tuvan anthroponymy]. Kyzyl, Editorial and Publishing Department of Tuvan State University Publishing house. 207 p. (In Russ.).

Suvandii, N. D. (2013) Sovremennoe sostoianie izucheniia onomastiki tuviskogo iazyka [Current state of studying onomastics of the Tuvan language]. Mir nauki, kul'tury, obrazovaniia, no. 6, pp. 362-364. (In Russ.).

Suvandii, N. D. (2018) Bichen Kyrgyzovna Ondar and her contribution to the study of the toponymy of Tuva. The New Research of Tuva, no. 3 [online] Available at: https://nit.tuva.asia/nit/article/view/785 (access date: 12.12.2019). DOI: 10.25178/nit.2018.3.1 (In Russ.).

Suvandii, N. D. (2019a) Ofitsial'nye i «vtorye» imena etnicheskikh tuvintsev Mongolii [Ethnic Tuvans of Mongolia: Official and 'Second' Names]. Oriental Studies, no. 4, pp. 661-668. (In Russ.). DOI: 10.22162/26190990-2019-44-4-661-668

Suvandii, N. D. (2019b) Slozhnye lichnye imena, obrazovannye imennymi chastiami rechi v tuvinskom iazyke [Complex personal names formed by nominal parts of speech in the Tuvan language]. Mir nauki, kul'tury, obrazovaniia, no. 3, pp. 404-406. (In Russ.).

Superanskaia, A. V. (1969) Struktura imeni sobstvennogo. Fonologiia i morfologiia [Structure of a proper name. Phonology and morphology]. Moscow, Nauka. 206 p. (In Russ.).

Chadamba, Z. B. (1999) Tuvinskie imena [Tuvan names]. In: Spravochnik lichnykh imen narodov RSFSR [Directory of personal names of peoples of the RSFSR], ed. by A. V. Superanskii and Yu. M. Gusev. Moscow, Russkii iazyk. 571 p. Pp. 174-177. (In Russ.).

Chadamba, Z. B. (1993) Sposoby obrazovaniia tuvinskikh lichnykh imen [Formation methods of the Tuvan personal names]. In: Voprosy tuvinskogo yazykoznaniya [Questions of Tuvan linguistics] / ed. by D. A. Mongush and B. I. Tatarincev. Kyzyl, Tuvinskii nauchno-issledovatel'skii institut yazyka, literatury i istorii. 128 p. Pp. 98-105. (In Russ.).

Submission date: 20.12.2019. 